
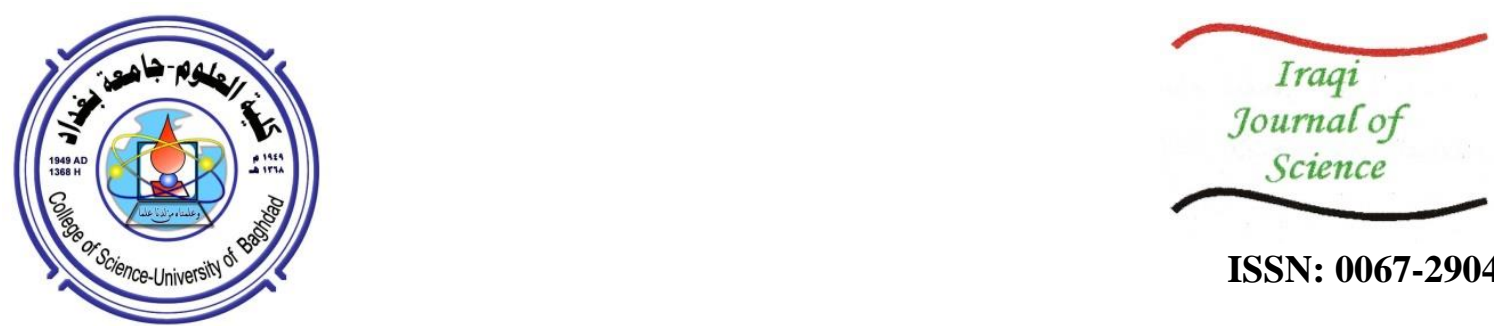

ISSN: 0067-2904

\title{
Detection of Pro-Inflammatory IL-8 and IL-12 in Iraqi Women Infected with Trichomoniasis
}

\author{
Hayder Z. Ali \\ Department of Biology, College of Science, University of Baghdad, Baghdad, Iraq
}

Received: $23 / 11 / 2020$

Accepted: 19/1/2021

\begin{abstract}
Trichomonas vaginalis is a unicellular flagellated protozoan that resides in female and male genital tract and considered the most prevalent sexually transmitted infectious parasite. The infection rate is relatively equivalent between male and female but trichomoniasis is usually asymptomatic in men. Primary triggering of host inflammatory response to this parasite is not fully understood and most studies address the local reaction of the parasite in female genital tract. In this study, two pro-inflammatory cytokines, IL-8 and IL-12, were investigated in the serum of infected women with Trichomonas vaginalis during acute and chronic stages of the disease. The results demonstrated that the level of IL-8 was significantly higher along the acute and chronic disease stages in female patients. However, the level of IL-12 was significantly increased in the acute group but exceptionally decreased in the chronic group of patients, in comparison with the control group. These results indicate that local infection of the vaginal Trichomoniasis may alter the levels of the studied inflammatory cytokines during infection.
\end{abstract}

Keywords: $T$. vaginalis, immune response, cytokines, vaginitis

التحري عن الانترلوكينات الالتهابية IL-8 و IL-12 في النساء العراقيات المصابات بداء المشعرات

$$
\begin{aligned}
& \text { حيدر زهير علي } \\
& \text { قسم علوم الحياة ، كلية العلوم ، جامعة بغداد، بغداد، العراق }
\end{aligned}
$$

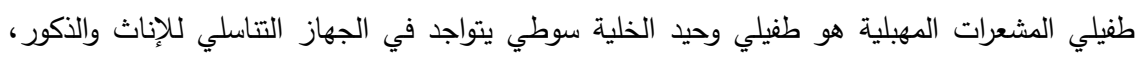

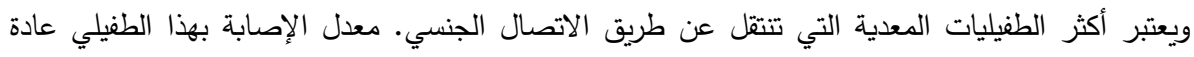

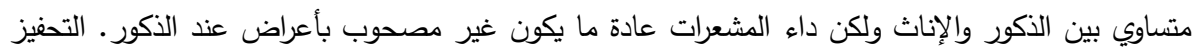

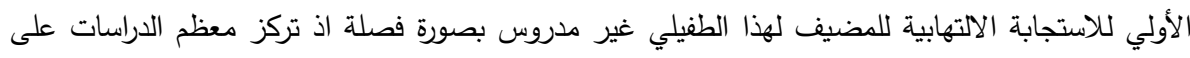

$$
\begin{aligned}
& \text { التفاعلات الالتهابية للطفيلي في الجهاز التناسلي للإناث. في هذه الدراسة ، تم التحري عن الثين من الإنيات }
\end{aligned}
$$

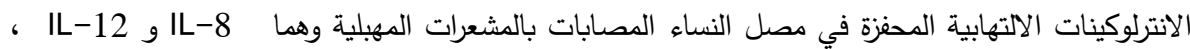

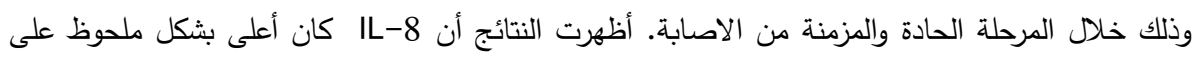

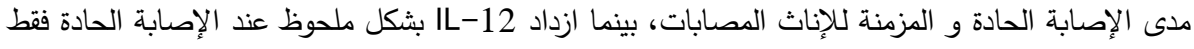

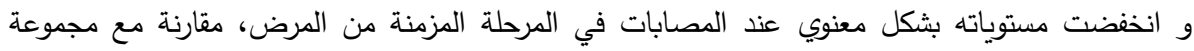

$$
\begin{aligned}
& \text { السيطرة. تثير هذه النتائج إلى أن الإصابة الموضعية لطفيلي المشعرات المهبلية قد اثرت على مستويات }
\end{aligned}
$$

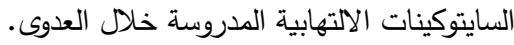

Email: hayder.zuhair@sc.uobaghdad.edu.iq 


\section{Introduction}

Human trichomoniasis is an obligate extra-cellular infection caused by a unicellular parasite, $T$. vaginalis a teardrop shape parasite which attacks female and male genital tract and is considered as the most non-viral sexually transmitted agent $[1,2]$. Recently, the parasite gained further consideration due to of the increase in the infection rate according to the WHO statistics in 2016; the worldwide prevalence of $T$. vaginalis infection is more than 270 million people annually [3]. T. vaginalis is endemic in Iraq; during the last decade, many epidemiological studies around many provinces such as Baghdad, Kufa, Najaf and Mosul, confirmed positive diagnosis of infection in women attending governmental hospitals $[4,5]$. The disease is usually asymptomatic in men, while in women, the asymptomatic phase is uncommon. The instigation of symptoms starts when white blood cells accumulate in the lower urogenital area and become in contact with the moving trichomonads [6]. Symptomatic female patients may undergo discomfort, dysuria, cervicitis, and vaginitis, associated with unusual vaginal discharge with foul-smell and possible infertility [7, 8]. In pregnant women, $T$. vaginalis infection may lead to preterm labor, abnormal infant weight and, if left untreated, the baby is most likely contracts live trichomonas form the infected mother [9]. Considerate investigation of the mechanism of immune response of host to T. vaginalis infection is essential for better understanding the infection strategy, early diagnosis, and treatment of the disease [10].

Host-parasite interaction is complicated in trichomoniasis; it depends on the host immune response towards trichomonads and the virulence factors of the parasite. This leads to pathological consequences by evading the durable physical barrier of the female genital tract after effective cytoadherence of the parasite to epithelial cells and the successful destruction and phagocytosis of target cells to carry chronic infection $[11,12]$. Systemic and local innate immunity of both males and females against infection is sex-dependent due to the special mucosal fluids during menstrual cycle and pregnancy in women [13]. Active or passive T-cell mediated immune response of the infected host play a vital role in controlling or exacerbating trichomoniasis. Previous experimental studies showed that $T$. vaginalis infection inhibits the expression of nuclear factor kappa-light-chain-enhancer of activated B cells (NF-kB) and its related Th-1 cytokines, such as TNF- $\alpha$ and IL-12 [11, 14]. Experimental mouse infection with T. vaginalis demonstrated low level of IL-2 and IFN- $\gamma$, both in serum and vaginal secretion. On the other hand, triggering the residing Natural Killer cells by the trichomonads activates the production of IFN-y, IL-10 and IL-8 by macrophages and cytotoxic $\mathrm{T}$ cells $[15,16]$. One of the major T. vaginalis antigens, Tva-actinin 2 , was found to trigger cytokine production in experimental vaginal epithelial cells infection, in which increasing levels of IL-10, IL12 , IL-6 and TNF- $\alpha$ were observed during the first 16 hours of screening [17]. In this study, two proinflammatory cytokines were investigated in the serum of women infected with trichomoniasis. The levels of IL- 8 and IL-12 were detected in the chronic and acute phases of the disease to inspect the possible immune effects of the parasite during infection.

\section{Materials and methods}

Sample collection Blood samples from 114 adult married women suspected with trichomoniasis were collected from different hospitals in Baghdad. Blood was centrifuged at $3000 \mathrm{rpm}$ and serum was collected and stored at -20 .

Diagnosis of trichomoniasis

All samples used in this study were diagnosed previously as acute or chronic infections as described earlier [18]. This confirmation test is not commercially available and was designed and purchased in collaboration with BIO-RAD, UK, especially for this study. BIORAD Company has developed a universal indirect ELISA kit for specific anti- $T$ vaginalis IgM and specific anti- $T$. vaginalis $\mathrm{IgG}$ for acute and chronic trichomoniasis detection, particularly for the purposes of this study.

Procedures and results of BIORAD indirect ELISA test for IgM and IgG analyses are not shown because they were performed and published earlier [18]. Number of samples was 18 and 16 for acute (IgM) and chronic (IgG), respectively.

Cytokines detection

The pro-inflammatory cytokines, IL-8 and IL-12, were purchased from Sigma Aldrich ${ }^{\circledR}$ (USA); the protocol of detection was sandwich ELISA, according to the manufacturer's protocol. Samples were screened in a 96-well plate for pretested women; 18 samples of $\operatorname{IgM}$ and 16 of IgG for trichomoniasis. Plates were read at $450 \mathrm{~nm}$ by ELISA reader [19]. The control group included 15 serum samples of 
apparently healthy women, with no known illness, and screened as above for IL-8 and IL-12 comparison.

Exclusion criteria

Samples from men, single women, and women under 18 years old were excluded in this study. Only married women with positive anti-T vaginalis $\operatorname{IgM}$ or $\operatorname{IgG}$, in comparison with control groups, were involved.

Statistical analysis

Statistical Package for Social Sciences SPSS (V.21) software was used for $t$ test analysis to detect the significant differences between test and control groups for each parameter, where $p$ value $\leq 0.05$ was considered significant.

\section{Results and discussion}

IL-8 level in acute and chronic stages

The results showed that IL-8 level was higher in both acute (IgM) and chronic (IgG) groups of infected women in comparison with the healthy group. The mean concentrations of IL-8 were 30.85 $\mathrm{pg} / \mathrm{ml}$ and $31.34 \mathrm{pg} / \mathrm{ml}$ in the acute and chronic groups, respectively, while a lower value in the control group was detected, which was equal to $22.47 \mathrm{pg} / \mathrm{ml}$ (Figure-1).

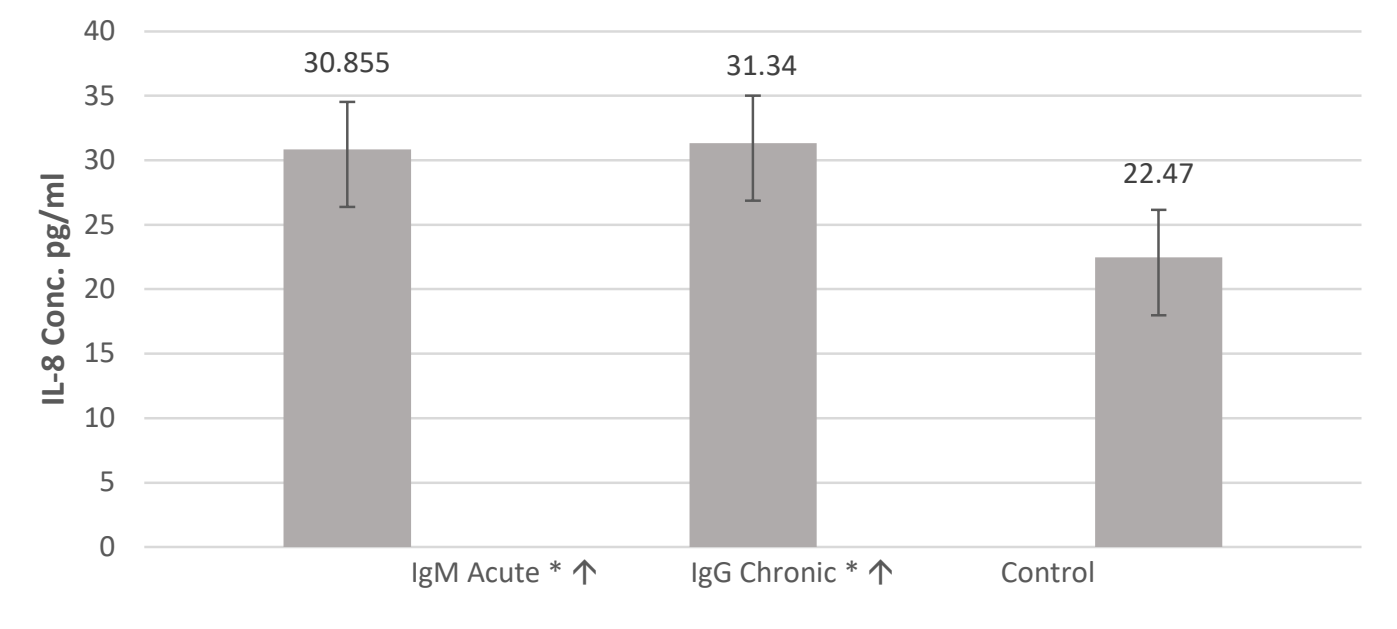

Figure 1-IL-8 level in acute and chronic trichomoniasis in comparison with control women, $*=$ significance $\leq 0.5$.

IL-12 level in acute and chronic stages

The results demonstrated that IL-12 level was higher in patients during the acute stage of the disease $(30.055 \mathrm{pg} / \mathrm{ml})$ in comparison with the control group $(23.053 \mathrm{pg} / \mathrm{ml})$. Whereas, the results of patients during the chronic stage of the disease exhibited a significance decrease of IL-12 level, with a mean concentration of up to $16.6 \mathrm{pg} / \mathrm{ml}$, as shown in Figure-2.

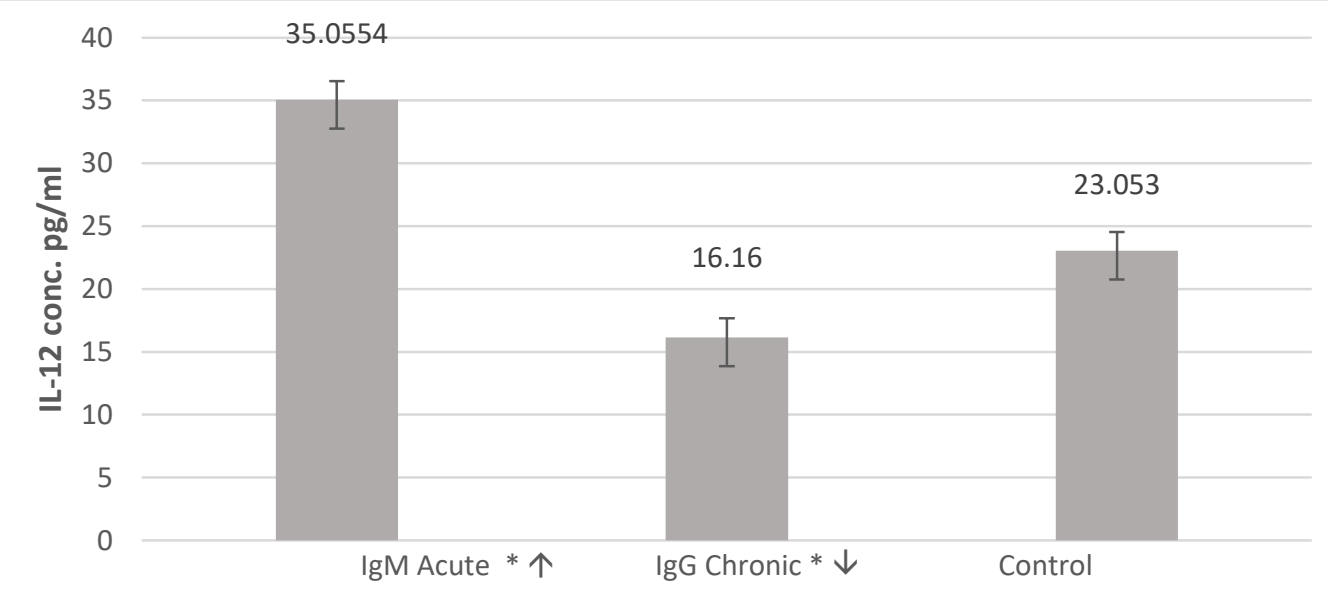

Figure 2-IL-12 level in acute and chronic trichomoniasis in comparison with control women, * = significance $\mathrm{p}$ value $\leq 0.5$ 
Furthermore, there was no significant difference between the acute and chronic groups for IL-8 values. On the other hand, the level of IL-12 in the chronic patients was significantly lower than that in the acute group, as shown in Figure-3.

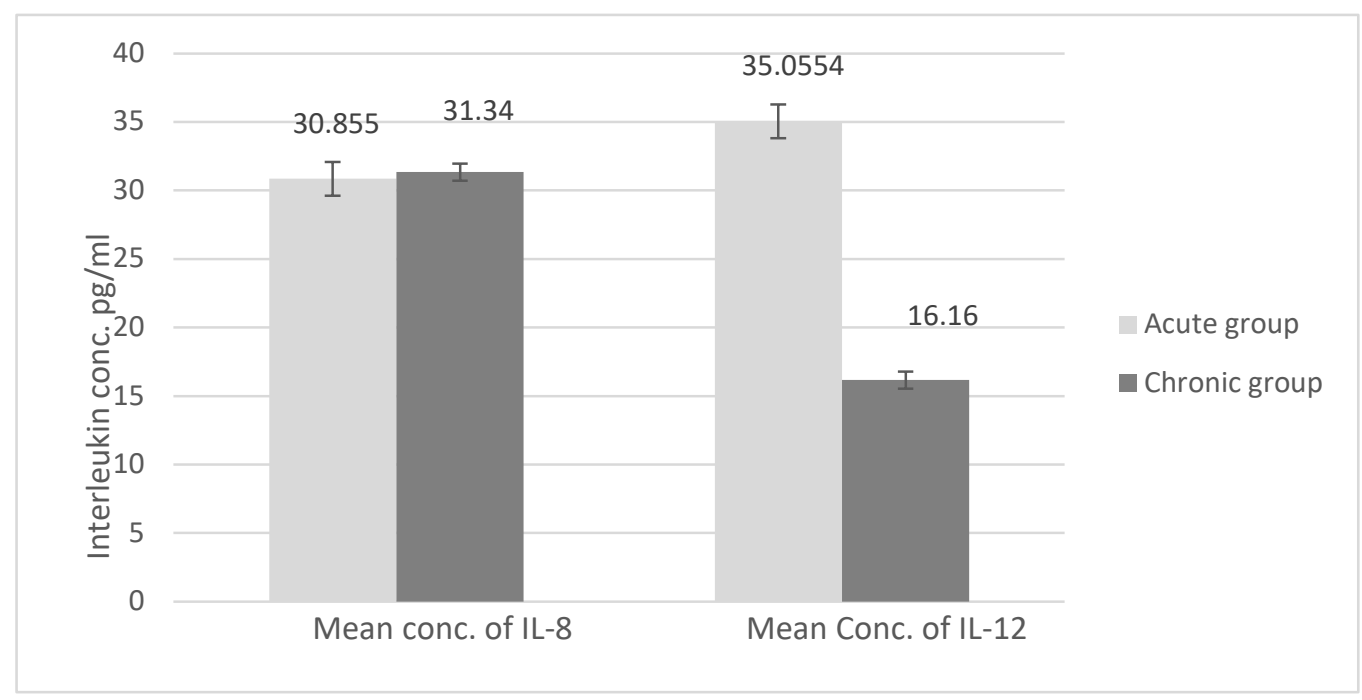

Figure 3-IL-8 and IL-12 mean concentrations in acute and chronic patients.

It was erroneously considered that $T$. vaginalis habitation of the vagina is harmless, until its role in pathogenesis of vaginitis was demonstrated [20]. However, the mechanism of immuno-pathogenesis and how the parasite can evade the immune system, as an extracellular pathogen, is still not wellidentified [2]. Several studies evidenced that infection with different sexual pathogens, including sexually transmitted diseases (STD) bacteria and T. vaginalis, is associated with increasing risk of human immunodeficiency virus HIV infection [21].

A previous study examined the endo-cervical inflammatory markers of women infected with $T$. vaginalis. They showed that the levels of IL-8, IL-6 and TNFr1 receptor were increased in association with $T$. vaginalis infection, but no correlation was detected for anti-inflammatory IL-10 [22]. The high expression of IL-8 is based on the fact that this local chemoattractant triggers the innate immune neutrophils in vaginal discharges, although it was also linked to high HIV infection risk [21, 23]. Moreover, bacterial lipopolysaccharide (LPS)-activated dendritic cells produce more IL-8 during $T$. vaginalis infection, which generates circulating specific $\operatorname{IgG}$ and $\operatorname{Ig}$ A towards the parasite. In addition, IL-8 was found to develop mucosal irritation $[2,11]$. In vitro culture of leukocytes proved that $T$. vaginalis stimulated these cells to produce $\mathrm{IL}-8$ and $\mathrm{iNO}_{\mathrm{s}}$. Furthermore, $T$. vaginalis lipophosphoglycan (LPG) was found to induce upregulation of IL-8 mRNA protein [20]. Additional research on IL-8 production in $T$. vaginalis infection confirmed the increased level of IL-8 in symptomatic women with trichomoniasis, after releasing TNF- $\alpha$ and IL- $1 \beta$ from damaged vaginal epithelial cells, where the concentration was up to $900 \mathrm{pg} / \mathrm{ml}$, suggesting that epithelial cells were provoked by LPG of live trophozoites [1].

Previous studies demonstrated the leukotoxic activity of $T$. vaginalis, in which IL-8 served as the primary inflammatory cytokine in response to infection and it is related to the severity of clinical presentation; in addition, the more damaged target cells occurred by the parasite, the higher release of IL-8 was followed; noting the fact that no phagocytosis is involved in pathogenesis [7, 24]. Moreover, it was verified that $T$. vaginalis promotes human macrophages and neutrophils to produce IL- 8 and the suppression of this interleukin and other chemokines facilitated the phagocytosis of host cells by the trichomonads [17, 25].

On the other side, this study demonstrated parallel elevation of IL-12 in the acute group but, surprisingly, it was decreased in the chronic group, in comparison with control. IL-12 is known as a pro-inflammatory cytokine, which prompts the differentiation of Th1. An experimental study found that $T$. vaginalis affects the expression of $\mathrm{IL}-12$ by the inhibition of NF-kB, a mechanism that is elicited by the parasite stimulation of anti-inflammatory macrophage marker IL-10, suggesting a 
potent invasion strategy $[11,26]$. An experimental research on the macrophage cell line RAW264.7 exposed to $T$. vaginalis showed that mRNAs of IL-12 and TNF- $\alpha$ were over-expressed during the first 2 hours of infection, but down-regulated after 8 hours [25]. rTv $\alpha$-actinin 2, a protein derivative of the parasite, was found to alter the immune response of dendritic cells, as confirmed by suppressing IL-12 but upregulating the anti-inflammatory IL-10 [17]. Nevertheless, innate immunity was found to have a minor effect on the parasite, in which a indistinguishable recurrent infection may occur in sexually active women, also in men suffering from prostate disorder, requiring better understanding of innate immunity towards this extra-cellular parasite $[27,28]$.

This study concludes a role of the extracellular T. vaginalis in modulating the responses of the systemic cytokines IL-8 and IL-12 in response to infection.

\section{References}

1. Fichorova, R.N., Trifonova, R.T., Gilbert, R.O., Costello, C.E., Hayes, G.R., Lucas, J.J., and Singh, B.N. 2006. Trichomonas vaginalis Lipophosphoglycan Triggers a Selective Upregulation of Cytokines by Human Female Reproductive Tract Epithelial Cells. Infection and Immunity. 74(10): 5773-5779.

2. Fichorova, R.N. 2009. Impact of T. Vaginalis Infection on Innate Immune Responses and Reproductive Outcome. Journal of Reproductive Immunology. 83(1-2): 185-189.

3. Menezes, C.B., Frasson, A.P. and Tasca, T. 2016. Trichomoniasis - are we giving the deserved attention to the most common non-viral sexually transmitted disease worldwide? Microbial Cell. 3(9): 404-418.

4. Al- Hadraawy, S.K., Al-Kafagy, S.M.M. and Al-Hadraawy, K.A. 2014. Molecular and immunological study for detection of IL-6 in men infected with Trichomonas vaginalis parasite in Al-Najaf province; Iraq. AL-Qadisiya Medical Journal. 10(8): 144-148.

5. Saheb, E.J., Kuba, R.H., Zghair, K.H. and Musa, I. 2016. A comparison between Trichomoniasis Infection and other Vaginal Infection among Females in Baghdad Governorate- Iraq. Iraqi Journal of Science. 57(1C): 545-551.

6. Zariffard, M.R., Harwani, S., Novak, R.M. Graham, P.J., Ji, Xin and Spear, G.T. 2004. Trichomonas vaginalis infection activates cells through toll-like receptor 4. Clinical Immunology. 111(1): 103-107.

7. Edwards, T., Burke, P., Smalley, H. and Hobbs, Glyn. 2014. Trichomonas vaginalis: Clinical relevance, pathogenicity and diagnosis. Critical Reviews in Microbiology. 42(3): 406-417.

8. Mielczarek, E. and Blaszkowska, J. 2015. Trichomonas vaginalis: pathogenicity and potential role in human reproductive failure. Infection. 44(4): 407-458.

9. Hamilton, H., Pontiff, K.L., Bolton, M., Bradbury, R.S., Mathison, B.A., Bishop, H., de Almeida, M., Ogden, B.W., Barnett, E., Rastains, D., Klar, A.L. and Uzodi, A.S. 2017. Trichomonas vaginalis in Brain Abscess in Neonate. Clinical Infectious Diseases. 66(4): 604-607.

10. Mutwiri, G.K. and Corbeil, L.B. 1998. Genital and systemic immune response in a murine model of Trichomonas foetus infection. Journal of Parasitology. 84(2): 321-327.

11. Nemati, M., Malla, N., Yadav, M., Khorramdelazad. And Jafarzabeh, A. 2018. Humoral and cell mediated immune response against trichomoniasis. Parasite Immunology. 40(3): 1-11.

12. Figueroa-Angulo, E.E., Rendon-Gandarilla, F.J., Puente-Rivera, J., Calla-Choque, J.S., CardenasGuerra, R.E., Ortega-Lopez, J., Quintas-Grandos L.I., Alvares-Sanchez, M.E. and Arroyo R. 2012. The effects of environmental factors on the virulence of Trichomonas vaginalis. Microbes and Infection. 14(15): 1411-1427.

13. Wira, C.R., Patel, M.V., Ghosh, M., Mukura, L., Fahey, J.V. 2011. Innate immunity in the human female reproductive tract: rndocrine regulation of endogenous antimicrobial protection against HIV and other sexually transmitted infections. American Journal of Reproduction Immunology. 65(3): 196-211.

14. Chang, J.H., Ryang, Y.S., Morio, T., Lee, S.K. and Chang, E.J. 2004. Trichomonas vaginalis Inhibits Proinflammatory Cytokine Production in Macrophages by Suppressing NF-kB Activation. Molecules and Cells. 18(2): 177-185.

15. Menezes, C.B. and Tasca, T. 2016. Trichomoniasis immunity and the involvement of the purinergic signaling. Biomedical Journal. 39: 234-243. 
16. Nguyen, P.V., Kafka, J.K., Ferreira, V.H., Roth, K. and Kaushic, C. 2014. Innate and adaptive immune responses in male and female reproductive tracts in homeostasis and following HIV infection. Cellular and Molecular Immunology. 11(5): 410-427.

17. Lee, H.Y., Ryu, J.S. and Park, S.J. 2017. Trichomonas vaginalis $\alpha$-Actinin 2 modulates host immune responses by inducing tolerogenic dendritic cells via IL-10 production from regulatory $\mathrm{T}$ cells. Korean Journal of Parasitology. 55(4): 375-384.

18. Bedair, N.H. and Ali, H.Z. 2020. Comparison of trichomoniasis diagnosis by microscopic methods and indirect ELISA technique in a sample of Iraqi women. Iraqi Journal of Science. 61(4): $742-748$.

19. https://www.sigmaaldrich.com/technical-documents/protocols/biology/elisa-protocols. html\# Sandwich \%20Assay\%20Procedure.

20. Singh, B.N., Lucas, J.J. and Fichorova, R.N. 2007. Trichomonas vaginalis: Pathobiology and Pathogenesis. In: Khan, N.A., et al. (Ed.). Emerging Protozoan Pathogens. London, UK: Taylor \& Francis. 411-455.

21. Guenthner, P.C., Secor and W.E. and Dezzutti, C.S. 2005. Trichomonas vaginalis-Induced epithelial monolayer disruption and human immunodeficiency virus type 1 (HIV-1) replication: implications for the sexual transmission of HIV-1. Infection and Immunity. 73(7): 4155-4160.

22. Jarrett, O.D., Brady, K.E., Modur, S.P., Plants, J., Landay, A.L., Ghassemi, M., Golub, E.T., Spear, G.T., Novak, R.M. 2015. T. vaginalis infection is associated with increased IL-8 and TNFr1 levels but with the absence of CD38 and HLADR activation in the cervix of ESN. PLOS one. 10(6): 1-11.

23. Song, H.O., Shin, M.H., Ahn, M.H., Min, D.Y. Kim, Y.S. and Ryu J.S. 2008. Trichomonas vaginalis: Reactive oxygen species mediates caspase-3 dependent apoptosis of human neutrophils. Experimental Parasitology. 118(1): 59-65.

24. Mercer, F., Diala, F.G., Chen, Y.P., Molgora, B.M, Ng, S.H. and Johnson, P.J. 2016. Leukocyte lysis and cytokine induction by the human sexually transmitted parasite Trichomonas vaginalis. 10(8): 1-19.

25. Fichorova, R.N., Yamamoto, H.S., Fashemi, T., Foley, E., Ryan, S., Beatty, N., Dawood, H., Hayes, G.R., St-Pierre, G., Sato, S. and Singh. 2015. .Trichomonas vaginalis Lipophosphoglycan exploits binding to galectin-1 and -3 to modulate epithelial immunity. The Journal of Biological Chemistry. 291(2): 998-1013.

26. Malla, N., Yadav, M. and Gupta, I. 2007. Kinetics of serum and local cytokine profile in experimental intravaginal trichomoniasis induced with Trichomonas vaginalis isolates from symptomatic and asymptomatic women. 29(2): 101-105.

27. Sena, A.C., Bachmann, L.H. and Hobbs, M.M. 2014. Persistent and recurrent Trichomonas vaginalis infections: epidemiology, treatment and management considerations. Expert Review of Anti-Infectious Therapy. 12(6): 673-685.

28. Kim, J.H., Moon, H.S., Kim, K.S., Hwang, H.S., Ryu, J.S. and Park, S.Y. 2019. Comparison of seropositivity to Trichomonas vaginalis between men with prostatic tumor and normal men. Korean Journal of Parasitology. 57(1): 21-25. 